\title{
ANDRÉS IBÁÑEZ O LA NOVELA ESPAÑOLA POSMODERNA
}

\author{
M. ${ }^{\mathrm{a}}$ DEL PILAR LOZANO MiJARES \\ Universidad Complutense de Madrid
}

\section{RESUMEN}

Existe un corpus bastante amplio de novelas españolas publicadas entre 1980 y 2000 que, de forma más o menos parcial, cubren aspectos concretos de las consecuencias de la episteme posmoderna en la narrativa española: la deconstrucción del sujeto y la realidad, el fin del tiempo y de la historia lineal, la ironía y la parodia intertextual, el fin de la utopía, el pastiche como herramienta estructural... Pero la demostración completa de todo lo que se puede describir teóricamente como novela española posmoderna se encuentra en los textos de Andrés Ibáñez: La música del mundo o El efecto Montoliu (1995) y El mundo en la era de Varick (1999). En ellas, Andrés Ibáñez propone una nueva forma de percibir la realidad que asume y excede los esquemas lógico-radicales de la modernidad: la mirada de la posmodernidad.

Palabras clave: Posmodernidad, deconstrucción, literatura posmoderna, novela española contemporánea, Andrés Ibáñez.

\begin{abstract}
Out of the Spanish novels published between 1980 and 2000, there is quite an extensive collection that deal with specific aspects of the consequences about the postmodern episteme in Spanish narrative in a more or less partial way: the deconstruction of ego and reality, the end of lineal time and history, the intertextual irony and parody, the end of utopia, the pastiche as structural tool... Nevertheless, the complete demonstration of all that can be theoretically described as Spanish postmodern novel can be found in Andrés Ibáñez's texts: La música del mundo o El efecto Montoliu (1995) and El mundo en la era de Varick (1999). In these novels, Andrés Ibáñez proposes a new way of perceiving reality that takes on and surpasses the logical-rational outlines of Modernism: the look of Postmodernism.
\end{abstract}

Key words: Postmodernism, deconstruction, postmodernist literature, Spanish contemporary novel, Andrés Ibáñez.

Muchas de las novelas españolas publicadas durante las dos últimas décadas delatan, de forma más o menos parcial, aspectos de la episteme posmoderna, es decir, las consecuencias que provoca la posmodernidad, en tanto que visión de mundo, en la narrativa.

Podemos observar esos aspectos en algunas obras de autores consagrados o de nuevas promesas como Eduardo Mendoza, Manuel Talens, Belén 
Gopegui, Lucía Etxebarria, Juan Manuel de Prada, Ángela Vallvey, Ángel García Galiano, Antonio Orejudo Utrilla, Arturo Pérez-Reverte, Juan José Millás o Antonio Muñoz Molina, entre otros:

1. La representación del mundo como problema ontológico, o lo que llamaremos la «imposibilidad del realismo», entendido en su sentido mimético tradicional: en la novela posmoderna, la realidad se desvanece, convertida en imagen, en simulacro, y el yo se conforma, irónica y lúdicamente, con esta pérdida. En palabras de Brian McHale (1987), la novela posmoderna trata de cuestiones ontológicas relacionadas con preguntas acerca de qué es el mundo, quiénes somos nosotros, cuál es la relación entre lo real, lo posible, lo imposible, etcétera. Los dos géneros fundamentales para la narrativa posmoderna serán, entonces, la novela fantástica y la novela histórica (redenominada como metaficción historiográfica), puesto que sirven como instrumentos para representar mundos ontólogicamente inestables. Estos dos géneros hablan de la no-distinción entre realidad e imagen de la realidad, la imposibilidad de diferenciar entre verdad y mentira, el abismo ontológico.

2. La deconstrucción del sujeto, del espacio y del tiempo. El sujeto (ya sea encarnado en el autor, el lector, el narrador o el personaje) ya no se considera una entidad coherente, generadora de sentido; su percepción de la realidad y la ficción no se articula en oposiciones binarias totales, sino en un juego inestable de coexistencia que termina con la superposición de ambas: es el sujeto esquizofrénico del que habla Fredric Jameson (1984). Este sujeto fragmentado y esquizofrénico imprime a los protagonistas de las novelas un afán de deconstrucción no solo de su propia identidad y psicología, sino también de su relación - o, más bien, incapacidad de relación- con los otros. De ahí que los temas recurrentes de la novela posmoderna española sean la incomunicación, la fragmentación de las emociones, la pérdida de sentido del mundo, la paranoia espacio-temporal, la ausencia de relación entre el cuerpo y la mente. El personaje se ha convertido en un ser itinerante, y arrastra con él al lector, copartícipe en el proceso de creación de la novela.

El sujeto débil posmoderno afecta al espacio y al tiempo. En los textos realistas y modernistas, era la percepción de un sujeto - el narrador o un personaje - la que organizaba el tiempo y el espacio narrativos. ¿Qué ocurre cuando el sujeto se desvanece? El resultado será un no-tiempo, enclaustrado en un presente plano, sin signos de identidad propios y dominado por la amnesia histórica, y un nolugar, múltiple y heterogéneo, que se construye y se deconstruye a la vez, un espacio identificado con la heterotopía foucaultiana, con 
«la Zona», en términos de McHale, o con los no-lugares de Marc Augé (2001).

3. La inmersión en la metaficción por medio de instrumentos como la recursividad, la parodia, el apropiacionismo y el pastiche. La novela posmoderna muestra el proceso mismo de codificar estrategias de significado, delatando su carácter ficcional. Así distrae la atención del lector desde el mundo proyectado hacia el medio lingüístico, haciéndole ver que no hay diferencia entre la realidad y la ficción. La construcción del mundo se reduce, al final, al resultado de un juego de palabras, puesto que, como nos enseña Jean-François Lyotard (1979), la realidad es una red flexible de juegos de lenguaje.

4. La incredibilidad hacia los grandes discursos de la razón y la búsqueda de otras vías cognoscitivas, simbólicas y míticas, para encontrar sentido. El desencanto posterior a la última revolución contra la razón, el 68, reafirma la imposibilidad de la utopía. Los radicalismos de cualquier tipo deben ser desechados y sustituidos por una tolerancia que, para muchos, no es más que indiferencia y neoconservadurismo, pero, para otros, la única salida (débil, eso sí). Esta tolerancia, lúdica e irónica, se concibe como la única manera de reconocer la creciente pérdida de sentido en el mundo y, aun así, seguir viviendo: aprobar el caos y adoptar una ética superviviente al proceso de fragmentación de las grandes certezas. El elemento lúdico, omnipresente en los textos, funciona como necesario distanciamiento, como relativización de las pequeñas o grandes tragedias que sufren personajes posmodernos con los que, como lectores, nos sentimos identificados; que nos enseñan a no tomarnos la vida demasiado en serio, a jugar, en el sentido de disfrutar, con el presente, que es lo único que poseemos, a recuperar una mentalidad infantil, mítica y simbólica que la razón físico-matemática, llevada a su aplicación extrema en la modernidad, nos ha arrebatado.

Desjerarquización, difuminación de las fronteras entre alta y baja cultura, hibridación genérica, exaltación del presente, nueva mímesis, parodia intertextual, polisemia y apertura, hedonismo..., todos ellos son rasgos que participan a la vez de lo formal y lo temático. Y en esta última síntesis de significante y significado, en esta unión de lo que se dice y cómo se dice, reside el éxito de la novela posmoderna española: no solo tematiza nuestro mundo posmoderno, sino que la forma de hacerlo nos lleva directamente a él, uniendo forma, fondo e interpretación. En estas lides es especialista Andrés Ibáñez.

Nacido en Madrid, en 1961, Andrés Ibáñez es autor de las novelas $L a$ música del mundo o El efecto Montoliu (1995; premio Ojo Crítico), El mundo en la era de Varick (1999) y La sombra del pájaro lira (2003). Como crítico, colabora con Revista de Libros, ABC Cultural y Babelia. Ha 
ganado la I edición del premio Bartolomé March a la crítica por una reseña sobre Thomas Pynchon, y el premio NH de relatos inéditos por su libro El perfume del cardamomo. También ha publicado un libro de poemas, El bulevar del crimen, y el cuento «No esperes», incluido en la antología Páginas amarillas.

Andrés Ibáñez pertenece al grupo de novelistas españoles de los noventa que José María Guelbenzu denomina «narradores de sabiduría»: «Son todos ellos narradores entre los treinta y cinco y los cuarenta años, han publicado sus primeras novelas o su novela de importancia en el decenio de los noventa y llevan sobre sus espaldas la presión indeseada de un grupo de veteranos que ha conquistado su lugar dejando muchas bajas por el camino y de un grupo de noveles arrebujados mayoritariamente bajo la bandera del ya tan mencionado show business» (J. M. Guelbenzu, 1998: 41). Guelbenzu se refiere, además de Andrés Ibáñez, a Belén Gopegui, Juan Miñana, Agustín Cerezales, J. A. González Saiz y Luis Magrinyà: «Independientemente del lugar que lleguen a conquistar, estos seis nombres son un ejemplo de resistencia contra la banalidad, contra el show business que se quiere hacer pasar por literatura (¿es que no tienen bastante con ser los reyes del show business?) y, sobre todo, son hijos de la curiosidad, de la duda, del deseo de saber. Lo suyo es el riesgo (ibíd:: pág. 43).

A pesar de no poseer una larga trayectoria ni una gran cantidad de títulos publicados, se le menciona en los estudios panorámicos más recientes sobre narrativa española contemporánea, como Del franquismo a la posmodernidad: la novela española (1975-1999). Análisis y diccionario de autores, de M. Mar Langa Pizarro (2000), Los nuevos nombres: 1975-2000. Primer suplemento, coordinado por Jordi Gracia (2000), o La novela española en el fin de siglo 1975-2001, de Santos Alonso (2003).

Este último, como Guelbenzu, también sitúa a Andrés Ibáñez dentro de una posible generación de los 90 (nacidos a partir de 1960), y concretamente en una tendencia llamada «novela alegórica, mítica y fantástica» que trataría «la creación de mundos imaginarios y la reflexión sobre aspectos cercanos a la metafísica y la estética» (S. Alonso, 2003: 50).

En general, se destaca su alejamiento con respecto a las propuestas más comerciales de la narrativa última y una cierta dificultad conceptual y estética provocada por, en palabras de Santos Alonso, su «tendencia al experimentalismo discursivo» (ibíd.: 189).

Sus novelas han despertado el interés de la crítica especializada. Ángel García Galiano les dedica un capítulo titulado, con acierto, «Andrés Ibáñez, creador de mundos» en su trabajo sobre narrativa española última El fin de la sospecha. Calas significativas en la narrativa española (1993-2003); las reseña favorablemente y valora «la irrupción de un escritor de largo aliento al que, en todo caso, habría que reprocharle (i) su desbordante ambición, su afán totalizador» (A. García Galiano, 2004: 194). 
La lectura de La sombra del pájaro lira provoca en José María Pozuelo Yvancos la siguiente alabanza: «puede que sea el escritor más importante de su generación» (J. M. Pozuelo Yvancos, 2004: 307). El crítico señala la novedad de sus planteamientos con respecto a los senderos tradicionales de la narrativa española: «Andrés Ibáñez es capaz de llevar al lector a unos matices inéditos, por su rica inventiva, en la novelística española» (ibíd.: 308).

En este último comentario coincide con Santos Alonso, para el que la obra de Ibáñez es «completamente ajena a las tendencias más exitosas del momento e incluso a la gran tradición de las letras españolas» (S. Alonso, 2003: 276), y con Guelbenzu, que reseña de la siguiente manera El mundo en la era de Varick: «He aquí una novela realmente sorprendente. [...] no hallo parecido alguno con ninguna otra narración publicada anteriormente en nuestro país de autor español, salvo con la primera novela del mismo Ibáñez, La música del mundo» (J. M. Guelbenzu, 2000: 42). Las fuentes de Ibáñez habría que buscarlas, según Guelbenzu, en Nabokov y los posmodernos, especialmente Pynchon.

Juan Trejo Álvarez también afronta la extrañeza de planteamiento narrativo de La sombra del pájaro lira y busca sus orígenes: «La escritura de Ibáñez entronca con las más poderosas y exigentes líneas de la tradición occidental (en sus páginas puede detectarse el aroma, entre otros, de Nabokov, Musil, Borges, Lewis Carroll o Tolkien), pero, por así decirlo, se sirve del poder de ese núcleo duro narrativo para desplegar temas no del todo frecuentes, o evidentes cuando menos, en estos pagos» (J. Trejo Álvarez, 2003: 28).

A estas mismas fuentes (Nabokov, Joyce, Pynchon...) se refiere tempranamente Andrés Ibáñez en una entrevista publicada por Pedro López Murcia en El Urogallo, a raíz de la publicación de La música del mundo. Y son las palabras del propio escritor las que nos servirán como guía para adentrarnos en su universo narrativo: «Yo creo que no hay diferencia entre poesía y prosa. Ambas son alimentos de la percepción. Querer romper las diferencias entre los géneros implica creer en ellos, y yo no creo. Simplemente, uso lo que me viene en cada momento. Lo natural, lo lógico, es vivir fuera de las categorías, y lo extraño es que haya novelas por un lado, y poesía por otro. Nosotros vivimos en la imprecisión, y sin embargo queremos que las cosas sean precisas...» (P. López Murcia, 1996: 23).

Cuando nos enfrentamos a las novelas de Andrés Ibáñez, lo más sencillo es decir que en ellas encontramos la demostración completa de todo lo que se puede describir desde un punto de vista teórico como novela posmoderna. Estamos ante un caso extremo: la narrativa de Andrés Ibáñez, como señalan los críticos, no tiene precedente en la literatura española, sino que se alinea directamente con propuestas que nos llevan a Borges, Castaneda, Lezama Lima, Nabokov, Tabucchi, Calvino y, por supuesto, el posmodernismo norteamericano, sobre todo Pynchon. En este sentido, podríamos 
pensar que se trata de una rara avis en el panorama español, pero sería más ajustado afirmar que ningún autor ha sabido, como él, expresar la episteme posmoderna de forma tan completa en la narrativa española, aun cuando muchos otros se hayan acercado desde distintos puntos de vista.

Dice el propio Ibáñez en su artículo «Paisaje para después de la posmodernidad»: «Lo que yo propongo es que nos convirtamos en libélulas, cuyos ojos múltiples les permiten ver al mismo tiempo distintas versiones de la realidad» (A. Ibáñez, 2002: 42). Y así es; sus novelas proponen una nueva mirada, una nueva forma de percibir la realidad que asuma y exceda los esquemas lógico-racionales de la modernidad: el espacio, el tiempo, la identidad, la relación causa-efecto... todo ello se trastoca para entrar en otra dimensión que, en el fondo, es bastante antigua, puesto que mira hacia culturas milenarias, o hacia nuestros propios orígenes, barridos por la fuerza de la razón.

Esta nueva mirada creativa tiene su homólogo más directo en las propuestas teóricas de Fredric Jameson: la posmodernidad supone un cambio en la percepción del tiempo, del espacio y de la identidad, y este cambio impone al arte la necesidad de proponer una nueva forma de mirar, lo que Jameson llama «diferencia radical», es decir, percibir la realidad no como algo fragmentado que remite al final a una unicidad, a una verdad última racional y a la medida del hombre - esta es la especialidad del arte moderno-, sino percibir los fragmentos como tales, como caos, dentro de un orden nuevo, el caos ordenado del que habla también Antonio Escohotado (1999) en Caos y orden.

Las novelas de Andrés Ibáñez, en fin, responden afirmativamente a las preguntas que lanzó el escritor en su artículo citado más arriba, en el que propone un arte simbiótico que combine los cuatro elementos que considera básicos, «la flor, el libro, el ángel y el ordenador» (A. Ibáñez, 2002: 42), es decir, la naturaleza o realidad física, la cultura, la mente o realidad psicológica, y las máquinas: «¿Es posible una literatura integrada en una simbiosis de máquinas, flores, ciudades, templos? ¿Es posible conciliar las palabras del poema con las del manual científico, la del pájaro y la del ángel?» (ibíd.: 40).

Podríamos seguir las líneas teóricas de Brian McHale y señalar en los textos de Ibáñez cómo se van cumpliendo, una a una, las características que describe. Parece como si el crítico norteamericano hubiera tomado sus novelas como textos base para la elaboración de Postmodernist Fiction, tal es la sorprendente afinidad entre teoría y práctica.

Sin embargo, recurriremos a Michel Foucault (1966) y su prefacio de Las palabras y las cosas: Andrés Ibáñez se propone pensar fuera de las estructuras que nos han sido dadas, que están construidas a priori, por la modernidad. Sigue, pues, los pasos de Jorge Luis Borges y su cuento $E l$ idioma analítico de John Wilkins. Y lo consigue. 
Analizaremos sus dos primeras novelas, que son las que conforman el edificio de su narrativa. La tercera, La sombra del pájaro lira (que será, probablemente, la primera de una serie de «novelas míticas»), no es más (ni menos) que la realización práctica, la consecución de lo que Ibáñez propone en La música del mundo o El efecto Montoliu y El mundo en la era de Varick. Comencemos por la primera.

La novela se plantea desde el principio como una fábula, como una historia que se sabe a sí misma narración: «la historia comienza con un muchacho que coge el tren al anochecer, con un viejo escritor [...]» ( $L a$ música del mundo, pág. 11). No es casualidad que la primera frase no respete las leyes ortográficas de las mayúsculas: es un falso comienzo. En realidad, no hay comienzo en la novela de Ibáñez, no hay principio, no hay inicio. Su existencia nos situaría en un tiempo lineal y causal, y no es el caso: el tiempo de esta novela es musical, y su filiación se hace explícita desde la primera página, incluidos los pentagramas.

El tiempo en La música del mundo es un motivo, una frase musical que se repite con variaciones pero que, en el fondo, es la misma. Los hechos que se van narrando son «episodios entrecortados que terminan en sí mismos y que no consiguen salir de la inmovilidad anónima de la naturaleza» (ibíd.: 12). No se dirigen hacia ningún fin ni recuperan un tiempo pasado: son autosuficientes y, por tanto, inmóviles. Así es, para Ibáñez, el tiempo de la historia: "parece que la música del bosque conoce ya toda la historia, desde mucho antes de que suceda» (ibíd.: 13). Todo lo que se nos va a contar, todo lo que vamos a leer, está ya ahí, en la naturaleza, en la realidad, como si fuera una grabación musical. Y, a modo de guía, Ibáñez nos indica cómo oírlo: los pentagramas son la clave de la estructura de la novela, el modo que tenemos que adoptar para leerla. El libro, así, se convierte en algo físico, no deja de ser nunca papel y tinta, y el propio autor se encargará, de tanto en tanto, de recordárnoslo.

«todo tenía su melodía en la música del mundo, la vida tenía su melodía y también era una melodía la muerte» (ibíd.: 16): en el sistema de representación de la novela, la realidad no se corresponde con las palabras, con un sistema lógico y ordenado, sino con ondulaciones temporales, es decir, con música. En este mundo, la conversación entre un perro y un gato en una calle perdida de Viena es completamente real, tanto como lo es Block, su protagonista principal, paseando por esa calle. Otra cuestión es que no seamos capaces de entender esa conversación, porque nuestra capacidad de pensar no alcanza a escucharla. Con este guiño cervantino, «El sol de Viena», primer capítulo, supone el primer movimiento de una sinfonía: el motivo de la huida, lo que se deja atrás, que se completará a modo de círculo con la huida de Países al final de la novela.

El narrador se inmiscuye continuamente en la historia — «sepamos, entonces, quién es Block» (ibíd:: 23)—: como un director de orquesta, marca 
los tiempos y dirige al lector. Le muestra el camino y le explica los pasos que ha de ir dando. No nos permite entrar en el sistema mimético de la representación, aun cuando nos esté contando una historia. Es como si estuviéramos escuchando dos voces al mismo tiempo: una que nos narra los hechos y otra que nos va diciendo «no olvides que esto es ficción». De este modo, lector y texto van situándose en el mismo nivel de diégesis. Veamos un ejemplo.

Leemos un diálogo convencional entre Block y su madre. Dentro de ese diálogo, se marca en cursiva una palabra, «nosotros», que llama nuestra atención: «-bueno, no te enfades... aquí no tenemos criados, sólo lo decía por eso... Karl, yo creo que nosotros lo vamos a pasar muy bien en París...» (ibíd.: 29). De repente, el diálogo se detiene por culpa de un extraño paréntesis: «(un recuerdo de Block)» (ibíd.). Tras el recuerdo, el texto se cita a sí mismo, la palabra «nosotros» reaparece para recuperar el discurso anterior, para continuar con el movimiento del diálogo: «nosotros: Tristenia, los campos de trigo...» (ibíd.: 30).

El papel en blanco se vuelve tangible, nos hace salir de la ficción en la que estábamos embebidos durante el diálogo para ser conscientes de esa misma ficción. La frase musical se detiene para introducir un movimiento nuevo, regresivo, del pasado, y luego, concluido el movimiento del pasado (el recuerdo de Block), volvemos al diálogo entre madre e hijo.

Ibáñez quiere que seamos conscientes de que estamos leyendo, no quiere que hagamos «como si», no quiere que finjamos la ficción, sino que entremos en ella del mismo modo que paseamos por la calle, con el mismo estatuto ontológico. El libro no es ficción de la misma manera que Andrés Ibáñez tampoco lo es cuando se dirige a nosotros, lectores, desde las páginas de su novela: «es un país demasiado grande, demasiado grande... sí, dijo Jaime doblando ruidosamente el periódico; un gorrión (atentos a estas yuxtaposiciones: un periódico, la inmensidad del mundo, un gorrión), un gorrión se había posado en una de las ramas del castaño de Indias que había frente a la ventana» (ibíd.: 93; la negrita es nuestra). Ibáñez no nos deja libres, porque quiere que nos demos cuenta de que no lo somos tampoco cuando no estamos leyendo.

Esta imposibilidad de ficción se une a la imposibilidad de ubicar espacial ni temporalmente la narración. Lo que, en teoría, es real se confunde con lo imaginario; el pasado (o aquello que, de forma hiperreal, identificamos como pasado: un ambiente posromántico y decimonónico, a veces incluso medieval) se une en nuestra percepción con el presente de la televisión o de una fiesta estudiantil de drogas, sensualidad y alcohol.

¿Dónde estamos? ¿Cuándo estamos? Hemos perdido los anclajes espaciotemporales, y no llevamos aún leídas treinta páginas. "Años de peregrinaje» es el pasado de Block, la huida con su madre de Tristenia, su vida en París y, después, en Viena. Es un movimiento regresivo, pero en él se 
incluyen ya prolepsis, el futuro: menciones a la Residencia, a Jaime y a Países. Pero es que no podemos olvidar la premisa con la que empezamos a leer: «parece que la música del bosque conoce ya toda la historia, desde mucho antes de que suceda» (ibíd:: 13).

«Block en Países» nos sume por completo en la desestabilización ontológica. No podíamos reconocer el espacio y el tiempo en el que se ubicaba la historia durante los dos primeros capítulos, pero, al fin y al cabo, se nos estaba hablando de tierras extranjeras, de una cierta lejanía geográfica que nos hacía más fácilmente asumible la inseguridad temporal. Los problemas comienzan cuando nos encontramos con Block paseando por una ciudad llamada Países en la que, sorprendentemente, hay una Biblioteca Nacional, un Círculo de Bellas Artes, calles llamadas Serrano y López de Hoyos (e incluso una gasolinera en la esquina entre López de Hoyos y María de Molina), pero también la «playa de Atocha». Atocha es real, es una estación de tren situada al sur de Madrid, igual que todo lo anterior pertenece a Madrid; pero Madrid, al menos hasta ahora, no da al mar; y tiene un río, pero no se llama Obrantes.

Ibáñez construye un espacio que es real e imaginario al mismo tiempo: es Madrid y no es Madrid, o al menos no es Madrid tal como lo vemos, del mismo modo que su parque Servadac es el Retiro y no lo es. ¿O será que no lo hemos visto bien nunca? La duda ontológica que provoca Ibáñez es tal que llegamos a plantearnos si Madrid tendrá mar y nunca lo habremos visto. Nadie es ajeno a la experiencia de haber visitado dos veces el mismo espacio y tener la sensación —o la seguridad - de que no se trata del mismo lugar. ¿Vemos imágenes de realidad, del mismo modo que en la televisión, y creemos que eso es la realidad? ¿Qué es la realidad? ¿Será cierto que el escudo de Madrid no está formado por un oso y un madroño, sino por un ciervo y grosellas?

La geografía de Países-Madrid se va identificando con la de la Biblioteca Nacional, con la del parque Servadac-Retiro y con la Región Confabulada, y es de la mano de un curioso personaje dieciochesco, Halifax y Farfán, como lo vamos conociendo.

Jaime descubre en la Biblioteca Nacional un volumen firmado por este ilustrado en el que describe un Jardín de Flores: «se trataría de un jardín de avenidas radiales, en cuyo centro se situaría un 'Ingenio Musical', explicaba Halifax y Farfán, gracias al cual todo el jardín, hojas y flores, árboles y arbustos, se regularía y crecería armónicamente...» (ibíd.: 59-60). El Jardín de Flores es, intuimos, el parque del Retiro, y somos testigos de cómo Jaime, Block y Estrella, en las ruinas de Almadrea, en el interior del parque, experimentan el poder de este ingenio. El sueño de Halifax y Farfán, un Jardín Botánico que fuera imagen del mundo y contuviera todos los conocimientos sobre el mundo, es el parque Servadac, el Retiro, que a su vez representa lo real. 
En este no-contexto, puesto que no sabemos muy bien dónde ni cuándo estamos, Ibáñez nos ofrece la ayuda de la teoría: el efecto de Montoliu, profesor de Jaime y Block. Nos encontramos, así, con lo esencialmente posmoderno de La música del mundo:

transformamos la casualidad en la historia de nuestra vida, convertimos la realidad multiforme en una obra de arte, y eso es el efecto; de un torrente de impresiones y percepciones inventamos un 'yo', del cúmulo de actos en los que participa o se ve envuelto ese 'yo' inventamos una 'vida', con increíble talento, arreglando aquí y allá, quitando y añadiendo, componemos unos recuerdos y los dotamos de una belleza y una felicidad que jamás tuvieron, ése es el efecto... (ibid.: 309).

El efecto, en el lenguaje de Lyotard y en el nuestro propio, es la metanarración o metarrelato, una estructura intelectual aprendida a priori que encierra nuestra capacidad de percibir la realidad. Es, pues, la episteme foucaultiana, e Ibáñez, como si de un personaje de Borges se tratara, se propone salir de los parámetros en los que Occidente ha enclaustrado la realidad: idea de tiempo, idea de causalidad, idea de identidad, y lo que aúna a todas ellas, el lenguaje. La imaginación es el medio para escapar del efecto. La libertad del ser humano reside, entonces, en su capacidad para desembarazarse de las cadenas del pensamiento.

Percibimos la realidad dentro de unos parámetros dados a priori y, de ese modo, la tergiversamos en el mismo momento de percibirlas. Lo que se propone en esta novela es percibir sin comprender, sentir sin pensar, porque es la única manera de salir del efecto y, por tanto, vivir realmente. Los procedimientos metatextuales de desestabilización ontológica, la desubicación espacio-temporal, la aparición continua del autor, la autocita, la digresión filosófica..., todo ello se dirige a hacernos conscientes del proceso de percepción, como si la novela fuera la vida. Ibáñez quiere que salgamos del efecto y el primer paso ha de ser leer de una forma distinta, leer sin comprender, dejarnos llevar por la intuición y seguir adelante.

Entonces, la novela funciona a dos niveles: el de la pura teoría, en el que Ibáñez intenta que comprendamos el problema, que lo procesemos intelectualmente; y el de la pura experiencia, la vivencia de la teoría. En este segundo nivel se sitúan las diversas experiencias de Jaime, Block y Estre1la: el paseo por el parque Servadac, la praderabruckner..., todo aquello que es vivencia sin reflexión lógico-racional. En el primer nivel, la novela de Ibáñez nos ofrece toda una teorización de la posmodernidad como episteme; en esto consiste la charla de Montoliu.

No es que el poder del efecto haya terminado, dice Montoliu, sino que nos hemos dado cuenta de que vivimos encerrados en él; esta es la base experiencial de la posmodernidad: el fin de la inocencia, el reconocimiento de que las metanarraciones por las que dirigíamos nuestra vida son sólo eso, metanarraciones. Este abrir los ojos, esta especie de anagnórosis, nos 
deja en el vacío, en la nada: ¿con qué llenarlo ahora? La crisis es válida, es necesaria: sólo significa ver la verdad.

Aquí sólo caben las respuestas personales a la crisis: podemos actuar como aquel personaje de Matrix que, frente al placer de un falso filete, elige la mentira del efecto; o como aquel otro que consigue ver la construcción como tal, como estructura, y decide luchar. Ibáñez, sin duda, apuesta por Neo mediante una nueva forma de percepción de lo real que parta del reconocimiento de que lo que conocemos hasta ahora y, sobre todo, cómo lo conocemos, es una estructura falsa que se superpone a lo real, una metanarración. El yo, el sentido, el tiempo, la causalidad, el espacio... todo ello forma parte de la gran construcción de Occidente. El primer paso consiste en reconocerlo, de forma racional o intuitiva; el segundo, salir de la construcción.

¿Pero cómo podemos pensar algo externo a nuestro pensamiento? Se trata de salir de la estructura foucaultiana, de ser capaces de crear una taxonomía como la de Borges, de categorizar fuera de las categorías que hemos aprendido, con medidas ajenas a nuestro propio pensamiento. No es simplemente lo opuesto, lo contrario, sino lo externo.

La experiencia en la praderabruckner es un ejemplo: consiste en percibir la música como espacio, no de forma racional, sino experiencial, que es, en resumidas cuentas, la única forma de escapar del efecto. El objetivo de Ibáñez con la praderabruckner consiste en hacernos sentir que espacio (pradera, mapa), música (pentagramas) y lenguaje (narración) están unidos. La novela deja de ser novela para convertirse en otra cosa, en una experiencia compleja en la que interviene no sólo el lenguaje, sino todos nuestros sentidos.

El dibujo del «otro jardín» en la isla de los Bucos (ibíd.: 160), la pradera donde se va a representar el adagio de la octava sinfonía de Bruckner, es la unión de los elementos básicos: lo masculino y lo femenino, la tierra y el cielo, las palabras y las cosas. Supone la deconstrucción de las diferencias, la percepción de la realidad como un todo de lo que el hombre forma parte. El final del capítulo es la conclusión de una sinfonía, un final ascendente y glorioso, completo en sí mismo.

Con la ceremonia de la praderabruckner, comenzamos a oír una frase que se repetirá a menudo: «el final de una época del mundo» (ibíd.: 153). Es el final relativo: final para un tipo de pensamiento, el de la cultura occidental de la modernidad; final de la separación del hombre con respecto a la naturaleza; del pensamiento dualista, disuelto en una interpretación holística de la realidad que es mucho más antigua que nuestros propios esquemas racionales.

La experiencia en la praderabruckner se completa con la visita de Jaime y Block a la casa de la calle José María Blanco White, relacionada con la Región Confabulada. Es la representación del mundo al revés, el espejo de Alicia. 
La posibilidad de entrar en la casa está directamente relacionada con la teoría del efecto de Montoliu: depende de abrir los ojos y descubrir que existe el referente (la cosa), y existe la palabra (el signo), pero que el significado es una construcción posterior que depende de la convención, del aprendizaje de un sistema que nos ha enseñado a adjudicar un sentido a una relación entre dos elementos previos. Si cambiamos la forma de percibir el significado, es decir, la relación arbitraria que une el referente con el signo, seremos capaces de utilizar el lenguaje de forma distinta y, entonces, dado que nuestra capacidad de pensar y percibir depende del lenguaje, de cómo conceptualicemos, podremos percibir de forma distinta la realidad. Cambiemos estas reglas y podremos entrar en el mundo de Alicia, en la Región Confabulada: cambiarán las normas que rigen nuestra percepción de la causalidad, del tiempo, del yo...

Una utilización distinta del lenguaje nos permite también entrar en la experiencia del paseo por el parque Servadac. El parque Servadac es el Retiro y no lo es: el cambio de nombre implica un cambio de visión. Es el Retiro por los datos objetivos que Ibáñez describe, pero la forma de verlo, los acontecimientos, todo es distinto a como lo percibimos normalmente. El problema ontológico comienza cuando, en el mismo nivel de realidad, se puede alquilar una barca en el estanque y sentir miedo de las sirenas que lo habitan, admirar la escena de Afrodita saliendo del baño, sentir lástima por el elefante Lamberto, curiosear por la isla de los náufragos del Titania... Es una nueva aventura fuera del efecto.

A través de Block, que experimenta el momento iniciático que le predice un viaje de conocimiento, Ibáñez nos avisa: ojo, lector, despierta, abre tu mente, aparta la necesidad de comprender y siente. Para sentir, la narración ha de convertirse en tridimensional, ha de llegar a todos los sentidos: los múltiples dibujos que Ibáñez va insertando en las páginas nos hacen ver La música del mundo como un mapa en clave. No se trata tan sólo de una hibridación de géneros o de sistemas artísticos como procedimiento textual, como provocación contra las normas que rigen la teoría literaria, sino de la comprensión de la novela como género total, que incluye todos los géneros; desaparece, así, el concepto de género.

Del mismo modo que podemos encontrar poemas, pentagramas o dibujos en una novela, el parque Servadac se nos desvela como el reino de lo posible, el espacio en el que todo puede suceder.

En este espacio de lo posible, Block experimenta la iluminación, el momento mágico que le descubre, por vía intuitiva, cuál es su lugar en el mundo, quién es; y se da cuenta de que esta iluminación ha de ser nuestro objetivo en la vida. La cuestión es no olvidarlo, recordarlo en contra del efecto. Y la única manera de lograrlo, el camino para obtener ese conocimiento de la realidad, es el oído, la música, no la vista, que nos lleva al objeto, y del objeto al concepto, y del concepto al pensamiento. 
Oír la música del mundo, entonces, no es más que salir del efecto, el camino para el conocimiento de una realidad verdadera, puesto que sólo comprendemos fragmentos de realidad. Y del mismo modo ocurre con la novela de Ibáñez: llega un momento en que dejamos de querer comprender, pero seguimos leyendo, y las palabras van penetrándonos sin buscar un sentido lógico, cognoscible; simplemente son, están ahí, y en cierta forma es la única manera de comprenderlas. Lo contrario sería estar dentro del efecto, propio de nuestro mundo occidental: "'comprender' significa 'desaparición', pero entonces, qué cruel resulta la estructura de la realidad para nosotros, occidentales, ya que el deseo de comprender [...] sólo termina cuando termina el deseo» (ibíd.: 244).

Almadrea simboliza esta desaparición, el fracaso de Occidente, su miedo hacia el caos de lo real. Construida en el centro de un parque que ha sido diseñado a la medida de la razón por ilustrados dieciochescos, Almadrea ha sido destruida por la naturaleza, y su abandono al caos provoca miedo e inseguridad en Block, Jaime y Estrella. Así, el parque Servadac, como un todo, representa el mundo, con su caos y su pretensión de orden. Pero el orden, impuesto, es externo, está fuera, y el caos reina a sus anchas en el interior de la construcción.

Almadrea está marcada por la muerte: el encuentro con el ave fénix y sus palabras desgraciadas hacen explícito el miedo, la maldición. Pero el miedo nos lleva también a la revelación. Todo el paseo por el parque Servadac conduce al momento climático de la experiencia con la piedra de la música, que les regala a los tres amigos una iluminación, la conclusión de una sinfonía: «percibió su vida como música, y comprendió de pronto que gracias a la música podía salir del tiempo y viajar por el tiempo en cualquier dirección» (ibíd.: 269).

Este momento último del paseo nos confirma que salir del efecto necesariamente supone olvidar el sentido de la vista, del concepto, de la palabra, para oír una música callada, distinta del sonido físico. La esencia de las cosas se identifica con esa música, un suave ondular que atraviesa las fronteras del espacio y del tiempo, pero también de la identidad. Es la epifanía de lo real, su manifestación.

La piedra de la música, intuimos, se relaciona con el aleph borgiano más allá de una obvia semejanza intertextual entre los dos momentos, la visión del aleph y la escucha de la piedra de la música. La diferencia fundamental reside en que, en Borges, este momento de conocimiento absoluto es imagen, mientras que para Ibáñez es sonido. En Borges, el olvido se hace necesario; en Ibáñez, el recuerdo es el objetivo. Borges sigue siendo un racionalista, está dentro del efecto, aunque roce el límite. Ibáñez quiere salir de él.

El paseo por el parque Servadac supone el clímax de la novela. Tras él, sólo podemos ir descendiendo hasta la conclusión final. Ibáñez va ce- 
rrando círculos: la charla teórica de Montoliu (efecto) se yuxtapone a la vivencia de la praderabruckner (música), y ambas nos conducen al parque Servadac (identificación de la salida del efecto y la experiencia de la música), para, por último, volver a Montoliu, pero un Montoliu muy distinto: «Montoliu en su camping» es un poema prosaico, es épica de lo cotidiano. Es curioso cómo, tras haber leído páginas enteras de pura prosa poética, Ibáñez elige el verso para narrar y nos arroja a la realidad del efecto, pero también de la metaficción. El poema incluye una de las referencias metaficticias más explícitas de toda la novela, la reflexión de lo que se narra, cómo se narra y, sobre todo, la reivindicación del no entendimiento, de la no comunicación con el lector. Ibáñez, autor, vuelve a sacarnos de la ficción para apelarnos.

¿Qué nos quiere decir Ibáñez con este poema, y, sobre todo, qué no nos quiere decir? ¿Estamos simplemente ante un guiño culturalista, la cita de sus fuentes - por otro lado obvias-, la rebelión contra el lector, al que parece que desprecia al negarle el sentido? ¿Se trata sólo de una demostración de poder, un jaque al rey de las reglas de la ficción, un demostrar con orgullo que desdeña las reglas y hace lo que quiere con sus palabras? Todo ello se encuentra en estos versos, una declaración de intenciones y una exhibición de fuerza: es él quien ostenta el poder. Pero también está hablando del acto de creación artística y del misterio que desvelará más tarde: la autoría de El lago Ariadna, supuesta novela de Montoliu, otro de los giros argumentales de la novela.

Con este poema se inicia el movimiento descendente de la novela: Montoliu se rinde, deja de luchar contra el efecto, se deja arrastrar por él y acepta su inserción en el mundo académico y profesional de la literatura. Es necesario este cansancio para la evolución de Block y Jaime: Montoliu debe desaparecer para que los dos protagonistas prosigan su camino, una vez que han aprendido de él todo lo que podían.

La caravana de Montoliu parece sufrir el mismo proceso de destrucción que la ciudad de Almadrea. La naturaleza, el caos, la ocupa por completo. ¿Significa que todo aquello que quiera huir del mundo racional está destinado a la destrucción por parte de la naturaleza? ¿La convivencia es imposible? ¿O más bien que el modo de luchar de Montoliu -y, por extensión, de Jaime, que acabará más o menos igual que Montoliu- es erróneo? La respuesta parece tenerla Estrella, cuyo protagonismo comienza a ser clave. De hecho, en un momento determinado, explica con claridad meridiana el concepto de tiempo que otros personajes (Montoliu, Otón, Jaime) han tratado de expresar a través de páginas y páginas de teoría: «-yo presiento la existencia de un tiempo por fuera del tiempo, dijo Estrella... yo lo llamo 'el transtiempo'... es algo así como el rumor de infinitas posibilidades de nuestra vida, un rumor que nos rodea, la posibilidad de infinitos mundos e infinitas vidas...» (ibíd.: 285). 
Estrella se nos ha ido revelando poco a poco. La vamos identificando como pieza clave en la necesaria huida del efecto, pues parece ser capaz de observar el mundo desde otro ángulo distinto al de Jaime y Block: está mucho más cerca de lo natural, más alejada de las grandes construcciones intelectuales que crea Jaime. Estrella lo ve todo más sencillo porque su cercanía al placer, al mundo natural de los sentidos, la hace más pura. Por ello, es más capaz que los personajes masculinos de sustraerse del pensamiento racional, que lucha contra sí mismo y acaba destruido.

El final del verano conduce, pues, al final de los magisterios. El tiempo de «Invierno de zarzamora» va mucho más allá de los planteamientos teóricos iniciales de la novela. Digamos que la palabra (la teoría) se hace carne: el tiempo realmente se convierte en lo que Estrella llama «transtiempo», un tiempo que ya ni siquiera se concibe como a la antigua usanza, circular, sino que es simultáneo, se estira, vuelve sobre sí mismo. Las cosas suceden y no suceden a la vez; los hechos se narran y se niegan. El universo ontológico ha quedado completamente destruido, o quizá ha entrado en otra dimensión, una dimensión einsteiniana en la que el tiempo, en realidad, es espacio. Los protagonistas de esta nueva dimensión serán Block y Estrella, cuyo amor enmarca los nuevos acontecimientos y la nueva percepción.

El aprendizaje de Block y Estrella se aleja, entonces, de lo puramente intelectual-especulativo, y se dirige hacia lo sensual-intuitivo. De ahí también el nuevo protagonismo de la Región Confabulada, un espacio en el que no han intervenido los maestros, las teorías, sino que ha sido objeto de descubrimiento vivencial por parte de los personajes desde el principio.

La relación con Borges se hace explícita en lo relativo a la teoría de la conspiración: la Región Confabulada parece ser la invención de un país imaginario dentro del mundo real. La metáfora borgiana del mundo como biblioteca se convierte en literal, se hace real en la unión intuitiva que realiza Jaime entre la Biblioteca Nacional y el parque Servadac, bajo la dirección de Halifax y Farfán. Sin embargo, es Block el que pone coto a la especulación: no hay que intentar comprender el mundo, nos dice, comprender el misterio, sino atravesarlo.

Vamos intuyendo que, en definitiva, la Región Confabulada es la realidad, está dentro de lo que entendemos como realidad. Designa no un espacio distinto, sino una percepción distinta del mismo espacio. Por eso puede estar en todas partes, y cualquiera puede formar parte de la conspiración. De hecho, Estrella expresa en voz alta sus sospechas de que Block es un agente, un mago. Pero eso no importa: lo importante es que, lo sea o no desde el principio, como lectores vivimos su proceso de aprendizaje del mundo, su alejamiento de la esfera intelectual. Por eso es él quien, cada vez más sabio, vive la posibilidad de un tiempo no lineal, un espacio o región «donde se confundían y disolvían todos los tiempos» (ibíd.: 310), el transtiempo de Estrella. 
La narración, entonces, se hace simultánea, e Ibáñez nos conduce por los caminos de un tiempo multilineal, espacial. Es Block quien, desde los pliegues de su colcha, observa y al mismo tiempo vive todos los caminos del tiempo. Los acontecimientos ocurren y no ocurren: Block está bajo su edredón y, al mismo tiempo, paseando por las calles de Países o comiendo en un restaurante el día de Navidad. No lo imagina, ni lo sueña, ni es una metáfora que podamos interpretar de alguna manera. Ocurre de ese modo.

Todo parece ir teniendo sentido. Las experiencias de los personajes en este transtiempo vuelven sobre lo ya acontecido, retoman afirmaciones, intuiciones o pensamientos anteriores para confirmarlos.

El final de la experiencia en el transtiempo nos conduce al segundo momento metaficticio más importante de la novela, junto al poema de Montoliu. En este caso, además, incluye una vuelta de tuerca ontológica, puesto que no es sólo Ibáñez quien nos habla desde las páginas de su novela, sino que son los propios personajes los que discuten sobre ella.

La desestabilización ontológica es completa: los personajes hablan de su propia novela, en un tiempo en el que los hechos ocurren y no ocurren, y en un no-espacio, la colcha de Block. Es lógico, entonces, que el final acoja todos los elementos de la novela al mismo tiempo. Volvemos, aparentemente, a la narración anterior más o menos tradicional, fuera del transtiempo: «como suele decirse en algunas novelas, 'los acontecimientos se precipitaban'... la mañana del 31 de diciembre [...]» (ibíd.: 363). Regresamos, en una especie de espiral, a la Sociedad Secreta de la Región Confabulada, esta vez materializada en una fiesta de fin de año en la embajada de Estonia, ubicada en la misma casa de la calle José María Blanco White.

En la fiesta aparecen prácticamente todos los personajes, cada uno arrastrando su propia historia: Otón y Zoé, Mencía, Montoliu, Jaime, Estrella y Block... Parecen transformarse los unos en los otros, se repiten situaciones que ya habían ocurrido, y todo ello sucede con la presencia de un misterioso fumador - trasunto del lector y, al mismo tiempo, agente de la Región Confabulada - que parece observar los acontecimientos sentado en una sala de proyecciones. Pero, en realidad, seguimos en el transtiempo: la fiesta de fin de año concluye en la colcha de Block, con una visión final que reafirma su rechazo a comprender.

«La música no termina, y el amor no termina, y eso es todo lo que debes saber...» (ibíd. 379): ¿a quién se dirige esta frase?, ¿es Block hablando consigo mismo?, ¿es Andrés Ibáñez apelando al lector? Llegados a este punto, tenemos que admitir que no importa: lo crucial es asentir a esta afirmación y dejarnos conducir al final de la novela, la apoteosis del amor de Block y Estrella.

La ruptura del transtiempo y el inicio del amor entre Block y Estrella nos devuelven al principio de la novela mediante una cita intratextual y al desvelamiento del misterio de la autoría de El lago Ariadna: «la historia 
comienza con un muchacho que coge un tren al atardecer, con un viejo escritor que espanta una polilla del círculo de luz y derrama una copa de vino sobre la hoja de papel, con el cielo azul y pálido de Viena y el cielo rosado de Países, combados y unidos en lo alto por la convexidad de un firmamento imaginario» (ibíd.: 387). Y nos damos cuenta de que, en realidad, el transtiempo ha gobernado toda la novela desde el principio, puesto que este primer párrafo ya es el transtiempo, la unión del principio y el final de la línea temporal y la unión de dos espacios en uno solo.

La frase inicial de la novela vuelve a repetirse, como un recuerdo insistente; el principio lleva al final y el final al principio. La sinfonía está avisando de que concluye. Y parece como si este preludio de final necesitara explicaciones: la explicación racional y metaficcional de Estrella al misterio de la novela — Block es un agente de la Región Confabulada- y la explicación absurda, la no-explicación, de «El monzón de mayo explicado a los niños», cita irónica del libro de Lyotard sobre la posmodernidad y único momento de toda la novela en el que se utilizan signos de puntuación. De este modo, parece decirnos Ibáñez, la pretensión de racionalidad, de explicación, sólo puede caer en la metaficción o en la teoría filosófica, inútil, a juicio de la burla del autor. Y en el centro de las dos explicaciones, el poema de Block (ibíd.: 402-404), una hermosa muestra de lírica del yo en la que el personaje intenta explicarse a sí mismo quién es en relación con el tiempo, y que va acompañado de la exégesis del propio poema.

Tras el interludio teórico y metatextual, los hechos se suceden con rapidez. El monzón de mayo trae el distanciamiento de Block con respecto a Jaime y Estrella, y una serie de reacciones en cadena, una especie de vulgarización, de normalización de la vida de los personajes: la calma que, como el monzón, precede a la tempestad. Se preparan para «el final de una época del mundo» (ibíd.: 408).

Para Jaime, muere su deseo de cruzar al otro lado, su investigación de la Región Confabulada, y culmina su inserción en el efecto. En cambio, para Block y Estrella, se abre la Región, que es el espacio del amor: la unión andrógina de Franz y Diotima, lo intelectual y lo sensual que anula el tiempo.

Cerramos la última página del libro e intuimos que la Región Confabulada es Países, desde el principio, y que Países es Madrid y es la realidad. Los personajes no se dan cuenta - ni nosotros, lectores- porque están dentro del efecto, y no pueden verlo. Block lo observa desde la altura que le dan el amor y la magia, bien porque desde el principio es un agente (como se dice en la novela), bien porque se ha transformado en un agente.

La música del mundo es, en realidad, una Bildungsroman, una novela de aprendizaje de la felicidad, que, en resumidas cuentas, consiste en vivir fuera del tiempo, fuera del efecto; e Ibáñez se permite, como si de cualquier buen narrador decimonónico se tratase, concluir con un deseo que 
predice la llegada de la felicidad a un mundo en que habremos podido librarnos del efecto, del pensamiento, y todo será música sin significado, puro ser en gracia:

llegará un mundo en que reinará la felicidad, los más sabios serán más felices... será un mundo no interpretado, un 'universo oído'... las cosas significarán menos, o apenas significarán, y esto nos permitirá vivir... entro por entre los árboles, en el jardín del mundo, y entonces comprendo... nuestro yo no será tan fuerte, no importará mucho la intención... si quieres saber algo del mundo del mañana, escucha, porque así será... las mujeres se pondrán trajes de lujo para ir al campo, los cristianos practicantes tendrán imágenes de Siva copulando con Kali... habrá entre las cosas nuevas relaciones, los significados se relacionarán de una manera diferente, o apenas se relacionarán... se debilitará el sentido, el efecto ya no tendrá apenas efecto... no se trata del mundo al revés, o el caos, sino de la libertad, de la pureza... cada acción será pura, sin intención, sin significado, y entre unas acciones y otras podremos curvarnos como melodías... libres del yo, nos libraremos de los grupos, de las consignas, ya no tendremos tanto miedo... (ibíd.: 472).

Pero este es un deseo proyectado hacia el futuro. Como el propio Ibáñez indica, La música del mundo es el libro de la «última generación del efecto Montoliu»: sus personajes, su autor, sus lectores... estamos dentro del efecto, no fuera. Quizá, en algunos casos, seamos más o menos conscientes del efecto (la posmodernidad como episteme no es más que la conciencia del efecto y el deseo de salir de él). Pero, con respecto a esta novela, nos situamos en el límite. Por eso somos buscadores, no hemos oído aún la música del mundo, aunque la hemos intuido. Belén Gopegui, Ángel García Galiano, Manuel Talens, Antonio Orejudo..., todos ellos y cada uno a su manera, son Block: han abierto los ojos, están buscando.

Tendrá que llegar una nueva generación para que podamos anunciar la muerte del efecto, un mundo que, aun siendo el nuestro, sea al mismo tiempo nuevo, y que se anuncia al final de La música del mundo: es la generación de El mundo en la era de Varick. La era de Varick es el tiempo en que el efecto ha concluido, al menos para los elegidos.

El mundo en la era de Varick es formalmente una novela más «realista» que La música del mundo, en el sentido de que su sistema de representación aúna lo histórico reconocible con la fantasía, concede mayor importancia a lo narrativo que a lo ensayístico y sitúa los hechos en un tiempo y un espacio no sólo identificables, sino cercanos al lector: es el final del siglo XX, nuestro siglo XX, en un Nueva York perfectamente real. Es, aparentemente, una novela más «normal».

El historicismo de la novela comparte con la metaficción historiográfica de autores como Manuel Talens o Antonio Orejudo Utrilla el uso de ciertos mecanismos narrativos posmodernistas como la inclusión de entidades o personajes históricos (Clinton y Gore, el New York Post, Cousteau, la ONU, Erik Satie, Charles Baudelaire...) en situaciones fantásticas o anacró- 
nicas; la cita de libros apócrifos (incluyendo lugar de edición, editorial, página $\mathrm{y}$, a menudo, traducción), junto a la cita de otros textos reales; y, sobre todo, la reinterpretación o reinvención de la historia a partir de la propia Historia. En esto consiste la era de Varick, un periodo que se inicia el 3 de febrero de 1961 cuando «la personalidad a la que llamamos 'Varick' se puso en contacto con nuestro mundo, por primera vez, a través de los labios de Janyce Alexander, la conocida médium y autora de cienciaficción» (El mundo en la era de Varick, pág. 31) y que coincide con las cuatro últimas décadas del siglo XX.

El comienzo de la narración se sitúa en el 30 de agosto del año 30 de la era de Varick, es decir, en nuestro año 1991. Ibáñez retrata con una extraña fidelidad los acontecimientos de estas últimas décadas del siglo XX, sólo que incluyendo a Varick, reinventando la historia. Así, George Cukor dirige una película sobre su aparición protagonizada por Spencer Tracy y Katharine Hepburn; Susan Sontag realiza la crítica de los libros que Janyce Alexander y su marido publican sobre su relación con Varick; Cousteau descubre a Varick en la isla de Poonokarele, paraíso espiritual en el que habitan el director de teatro Peter Brook y la actriz Shirley McLaine.

La mímesis, por tanto, es verosímil: podría haber sucedido así. De hecho, así ocurrió: miedos finimilenarios, sentimientos de apocalipsis; guerras absurdas; el resurgir de nacionalismos y fundamentalismos, con su carga de fascismo racista e irracional. Todo lo que describe Ibáñez es real, sigue siendo real; quizá Varick sea real, pero no lo sabemos aún. ¿Qué es, entonces, Varick?

Varick, ser de otro planeta, cuya peripecia recuerda enormemente al Gurb de Eduardo Mendoza, es un nuevo Cristo, un profeta, tanto como lo son Mr. Alkan o el Hombre del Violín: seres que intentan traer la buena nueva de un mundo posible y que, sin éxito, tratan de abrirnos los ojos a una percepción distinta de la realidad. Y, como Cristo, Varick, enamorado de la Tierra, tendrá que morir para que los elegidos - los varibabies y todos aquellos cuya percepción de lo real excede el límite de lo lógico-racionalelijan el camino del peregrinaje para alcanzar la tierra prometida: el Monasterio Perdido, Demonia, el Planeta Análogo. Pero su ideología es la noideología: no impone normas ni mandamientos; no exige más camino que la búsqueda de lo real en el interior del yo. En este sentido, es un Cristo posmoderno, impreciso y contradictorio, y su mensaje coincide con el futuro que Ibáñez predice al final de La música del mundo.

La generación que nace en la era de Varick son los varibabies, entre los que se encuentran Marcelo y Rita, los protagonistas de la novela. Marcelo, aprendiz de escritor (su novela inacabada, La conjuración china, es causa de una inmensa frustración para su autor), vive alejado de la experiencia, sintiendo que, a pesar de sus múltiples intuiciones de ilumina- 
ción, de lo que él denomina la sensación de «ENTONCES COMIENZA», nada sucede en realidad.

El centro de su vida, con diecisiete años, se sitúa en la lectura de Vida en el planeta Demonia, de W. Lycaeides, «que constituía una fantástica y a ratos fantasmagórica descripción de un planeta imaginario, reverso exacto, imagen especular, de nuestro planeta querido y conocido, la Tierra» (ibíd.: 63). Es la historia del Planeta Análogo, que a su vez nos recuerda a la Región Confabulada de La música del mundo. La diferencia fundamental con respecto a nuestro mundo «radicaba en el casi absoluto desinterés de los demonianos ante la idea de progreso» (ibíd.: 64): allí el tiempo, lejos de ser lineal y teleológico, puede bifurcarse en dos ramas paralelas.

Para Marcelo, Demonia es la realidad, puesto que allí las cosas suceden, dejan de ser imprecisas. Pero la intuición no llega nunca a cuajar, y Marcelo se pasa la vida esperando.

Su niñez nos conduce a la geografía del Madrid de La música del mundo - el monzón de mayo, las clases en el Abuelo del Mar, la isla de Fontibrol... - y a su amistad con Daniel, que reaparecerá más tarde como el periodista que narra la aparición de Varick en la isla de Poonokarele, durante una expedición de Cousteau a bordo del Calypso.

El relato de sus aventuras infantiles con Daniel nos descubre a un Marcelo que, sorprendentemente, conocía ya desde niño la existencia del Planeta Análogo -Eleusis, Demonia, el Planeta de los Sueños- y la leyenda del Monasterio Perdido. El problema radica en que, a medida que nuestro protagonista va creciendo, parece olvidar sus enseñanzas y encerrarse en un mutismo frustrado.

Daniel desaparece pronto de la vida de Marcelo, que inicia tras la universidad un peregrinaje por Oriente en busca de precisiones, de sentido. En Nueva York encontrará al sustituto de Daniel: Tebaldo.

Tebaldo será su guía en la edad adulta. Este personaje no sólo intuye la realidad del Planeta Análogo, sino que llega a ver a su análogo por las calles de Nueva York y a recibir llamadas telefónicas de Demonia. Gracias a él, Marcelo comienza a acudir a las sesiones de la Sociedad Filarmónica, un grupo de personas que se reúnen para, a través de la improvisación musical y la lectura de pasajes del libro de Mr. Alkan, relacionado con la leyenda del Monasterio Perdido, alcanzar un estado de la conciencia que les permita recordar lo que han olvidado: que están vivos, que la realidad no es tal como la ven a través de los ojos del pensamiento.

En realidad, se trata de luchar contra el Sistema. Tal como le explica Rita a Marcelo, los seres humanos, en terminología de Varick, somos cogitófilos, es decir, amantes del pensamiento, de Armakidjj, el parásito que nos mantiene dentro del Sistema.

En su lucha contra Armakidjj, Marcelo se enfrenta al problema del sujeto, a la multiplicidad de su identidad: «- Hay algo que me preocupa 
—dijo Marcelo con los ojos bajos-. Algo así como una difracción en el interior de la psique, un punto donde el YO se disocia en partes tan heterogéneas o incluso tan contradictorias entre sí que cualquier noción de unidad de sujeto queda destruida» (ibíd.: 251). Estamos ante el yo posmoderno, deconstruido, incapaz de ser absorbido en una unidad superior. La respuesta de Tebaldo le sume en la contradicción, puesto que el verdadero yo es un estado de la conciencia que no pertenece al mundo del pensamiento.

La dificultad final radica en que Marcelo, a pesar de ser un varibaby, es, al mismo tiempo, un cogitófilo radical, lo que le distancia de Rita, mucho más cercana a través de la danza al mundo de la naturaleza, ajena al pensamiento.

El problema de la identidad va unido al problema del lenguaje. El lenguaje forma parte del Sistema, del pensamiento, y, para Marcelo, escritor frustrado, el lenguaje es la única manera de relacionarse con el mundo: busca lo que Wittgenstein denominaba das erlösende Wort, la palabra que deshace los nudos; la palabra exacta, precisa. Tebaldo niega la posibilidad de esta palabra, puesto que las palabras son parte del nudo, y sitúa la salida fuera del pensamiento, en otro estado, en alcanzar una forma de percibir la realidad externa a las palabras.

Rita es el álter ego de Marcelo. Así como Marcelo busca en la escritura la apertura de su percepción de la realidad, ella la busca en la danza. Aprende del ballet clásico la negación, la aberración de encerrar la vida, la forma de su cuerpo, en una idea o estructura a priori. Frente al ballet clásico o a cualquier otra forma de danza, Rita busca la expresión a través de su cuerpo, de la improvisación: la «danza del ser interior». En esta búsqueda, su proceso de aprendizaje durante la adolescencia pasa por la lectura de un libro clave, como en el caso de Marcelo: Mi vida, de Isadora Duncan.

También, como Marcelo, viajará a Oriente en busca de respuestas, de esa «danza del ser interior». En Estambul encontrará la otra ciudad, Terra Merveille, situada en el Planeta Análogo, de la mano de Mr. Alkan. Su proceso de aprendizaje es más rápido que el de Marcelo. De hecho, cuando ella vuelve de Estambul, se encuentra en una terraza, en Valencia, con un Marcelo sumido cada vez más en las imprecisiones, a punto de partir hacia Oriente; y cuando Marcelo, ya en Nueva York, comienza a visitar Terra Merveille en sueños durante sus ataques de narcolepsia, Rita es capaz de reconocer el espacio porque ya lo había visitado: cuando Marcelo va, Rita ya ha vuelto.

El espacio protagonista, Nueva York, un Nueva York muy hispano, aparece con los atributos que le son propios: Central Park, el Village, las Torres Gemelas... No hay esa continua desestabilización ontológica del espacio que vimos en el Madrid de La música del mundo, en el que los es- 
pacios eran y no eran al mismo tiempo. Esta vez, Ibáñez propone la existencia de un espacio análogo: Demonia, el Planeta Análogo, que no es tanto otro espacio distinto sino otra percepción del mismo espacio, y cuya existencia intuyen, o incluso ven, algunos de los protagonistas de la novela.

Esta intuición será confirmada en el capítulo «Memoria del barrio de los magos por 'Verdamar'», en el que la gata Octaviana María narra sus peripecias en el Planeta Análogo. Pero el Planeta Análogo no es sólo un espacio mágico en la novela, sino toda una teoría de los mundos posibles que implica una percepción de la realidad absolutamente posmoderna.

Marcelo, tras una sesión de escucha en la Sociedad Filarmónica, en la que siente la armonía de la música inármonica y caótica que producen sus participantes (es decir, el orden del caos), experimenta un momento de iluminación, consigue salir de su propio pensamiento y verse a sí mismo; escucha la voz de Varick en su interior y su sensación de «ENTONCES COMIENZA» se hace realidad: «¡Despierta, Marcelo! ¡Esto no es un sueño! ¡Es todo verdad!» (ibíd.: 296). Entonces, es consciente de que, sin abandonar Nueva York, camina por las calles de la ciudad análoga, Terra Merveille, y siente todo aquello que es propio del Marcelo análogo: «Se sintió interiormente hermoso, reconoció en un instante los miles de delicadas sensaciones que constituían su persona interior, las bellezas tanto tiempo buscadas, los paraísos fugazmente entrevistos por su mente creadora de tormentos y delicias, los cielos de la otra ciudad, las señas y particularidades, en fin, de otra vida que podría ser su vida» (ibíd.: 295).

Este es el momento que precede a las «Memorias», que comienzan justo en la página 300 de la novela, el centro del texto. Ibáñez nos ha preparado el camino para la comprensión del Planeta Análogo, y la experiencia de Marcelo, junto con las extrañas llamadas telefónicas que recibe Tebaldo o la búsqueda de Rita de su ser interior a través de la danza, encontrarán su explicación en Demonia.

Erumburgo, la ciudad en la que se desarrollan los hechos de las «Memorias», es el Nueva York de Demonia. Del mismo modo, existen una Rita análoga, famosa bailarina del grupo de Mr. Alkan que ha conseguido encontrar y expresar su «danza del ser interior», casada con Herr Tebaldo y amante de Marcel, escritor de éxito que llega a hablar por teléfono con su análogo, Marcelo. Como la Tierra - Terra en la narración de Octaviana María-, Demonia posee también su Planeta Análogo: Ardis.

La diferencia radica en que los habitantes de Demonia son plenamente conscientes de la existencia de Terra y de sus moradores; de hecho, Maude, dueña de Octaviana María, se cruza con un Marcelo dormido por las calles de Erumburgo. La comunicación entre los distintos espacios es fluida y sus cauces son múltiples. Pero, mientras que los habitantes de Demonia los conocen e incluso utilizan, para los de Terra se reducen a creencia, a fe en las enseñanzas de Varick. 
La realidad en el Planeta Análogo es igual y, al mismo tiempo, muy distinta con respecto a la de Terra. En cierto sentido, sufren los mismos problemas que en Terra. Las peripecias de Octaviana María con Antínoo, el gato de Baudelaire, persiguen el mismo fin que las que viven Marcelo y Rita en Terra: conseguir ver la realidad tal como es. Sus protagonistas acaban, también, en un peregrinaje a bordo de la Gran Máquina en busca de Orplid, la Tierra Prometida, para luchar contra la gran peste que procede de Terra, Armakidjj. Este final predice la conclusión de los protagonistas de Terra, el peregrinaje a bordo del Kulffenio II (y también el final de La sombra del pájaro lira).

Sin embargo, en Demonia, los personajes análogos parecen haber alcanzado sus objetivos: Rita y su danza, Marcelo y su novela, Tebaldo y su música. Por otra parte, existen personajes que, sin dejar de ser quienes son, viven en ambos mundos a la vez: el Hombre del Violín, Mr. Alkan y la propia Octaviana María.

El tiempo es distinto también en los dos mundos. La narración de Octaviana María se sitúa en 1898, y vemos pasearse por ella a Charles Baudelaire y a Erik Satie. El ambiente que se describe es, efectivamente, finisecular, tanto como lo es el de Terra, sólo que un siglo anterior. Pero es que el tiempo en Terra tampoco es como lo conocemos normalmente, como se nos ha enseñado a conceptualizarlo: lineal, ordenado.

La novela comienza, según se nos indica, el 30 de agosto del año 30 de la era de Varick, el día que Marcelo y Rita se conocen en el Spanish Theater de Manhattan. El 3 de febrero, día primero del año 30 de la era de Varick —es decir, seis meses antes del comienzo de la novela-, los medios de comunicación dan la noticia del descubrimiento de Varick en Poonokarele, y Marcelo a estas alturas ya está enamorado de Rita. Por otra parte, el capítulo «Libro de los sucesos de otoño» es una analepsis con respecto al hilo narrativo principal, y narra los meses que precedieron al descubrimiento de Varick en forma de pez. En este capítulo se cuenta la decisión de cambio de Marcelo, su enamoramiento de Rita, su deseo de adelgazar, sus clases de yoga, su rechazo de La conjuración china, su inmersión en la mística de Varick. Por último, Varick muere el 1 de abril del año 30, y el 2 de abril Rita y Marcelo embarcan en el Kulffenio II, cuatro meses antes de que se hayan conocido.

¿Es la cronología de la era de Varick inversa, o es su tiempo inverso? En nuestro sistema temporal, Marcelo no puede estar enamorado de Rita si todavía no la ha conocido. ¿Se ha confundido Ibáñez al situar el inicio de la novela en el año 30?; ¿o se han confundido los narradores, las gentes de Ardis?; ¿o acaso es Marcel, el análogo de Marcelo, el verdadero escritor de El mundo en la era de Varick y, dado que posee una percepción del tiempo propia de Demonia, no coincide con la de Terra, con la nuestra?

No sólo la extraña cronología de El mundo en la era de Varick nos 
sume en la perplejidad, sino que la misma identificación del narrador supone un problema ontológico.

Al comenzar la novela, nos encontramos con un narrador omnisciente en grado sumo; es decir, una tercera persona que no sólo incluye rasgos de la omnisciencia tradicional, como la capacidad de inmiscuirse en la narración, sino que, además, se sitúa físicamente por encima del mundo. Son los compañeros de Varick, habitantes de Ardis, el Planeta Análogo de Demonia, quienes navegan por el aire a bordo de un globo aerostático en su busca, y observan y narran los acontecimientos con el detallismo del que todo lo ve, cerca y lejos, dentro y fuera, como si Nueva York y sus habitantes estuvieran dentro de una bola de cristal.

Sin embargo, al llegar a las «Memorias» nos encontramos con que Marcel, ser análogo al Marcelo de la Tierra, está escribiendo una novela que coincide con El mundo en la era de Varick, titulada La conjura contra Ardis. ¿Es, pues, Marcel trasunto de Andrés Ibáñez? ¿O simplemente se trata de una metáfora que nos indica que, en realidad, el mundo tal como lo conocemos es, de hecho, el Planeta Análogo, que la realidad es como la que se nos describe en Demonia y que todos nosotros podríamos ser magos?

El argumento de La conjura contra Ardis — que en realidad es la novela análoga de Vida en el planeta Demonia - resume la teoría de los mundos posibles, clave para comprender la ontología débil y vacilante de la posmodernidad. Marcel se lo explica a Octaviana María mediante una metáfora borgiana: sitúa una vela entre dos espejos y su imagen multiplicada hasta el infinito nos impide dilucidar cuál es la real y cuál no, porque el objeto y su imagen adquieren el mismo estatuto ontológico. ¿Cuál es el Planeta Análogo y cuál es el Planeta Real? Para Terra, el análogo es Demonia; para Demonia, el análogo es Ardis, y así indefinidamente.

La destrucción ontológica se completa cuando Marcel afirma que la vela original —el sujeto original, el planeta original - no existe: no es más que una teoría, el mundo de las ideas de Platón. Y la salvación, la lucha contra el pensamiento llevada a cabo por Mr. Alkan y por Varick, parece inútil.

¿Cuál es la narración original y cuál es la análoga? ¿Cuál es la realidad y cuál es la fantasía? No existe diferencia: el original y la copia son lo mismo.

La música del mundo y El mundo en la era de Varick están íntimamente relacionadas. Más allá de ciertos guiños que salpican el texto (como el hecho de que Varick describa a los humanos como seres dominados por el «efecto Montolieux» (ibíd.: 36); o la repetición en ambas novelas de la frase «el final de una época del mundo»; o la cita intertextual de obras de Borges y Lezama Lima), la filosofía que subyace tras ambos textos coincide en señalar la imposibilidad de ser en un mundo gobernado por el pensamiento lógico (que en El mundo en la era de Varick se denomina Armakidjj, el parásito, o el Sistema; en La música del mundo, el efecto; y 
en La sombra del pájaro lira, el insecto), y la necesidad de abrir los ojos, de despertar, para conseguir vivir realmente y ser conscientes de que existimos. El camino para este despertar común coincide también en las dos novelas: la imaginación.

Pero, sobre todo, coinciden ambas novelas en su final, ese «final de una época del mundo» que reseñamos más arriba. El 3 de febrero, día primero del año 30 de la era de Varick, cumpleaños de Marcelo, salta la noticia de la aparición de Varick en forma de pez a los medios de comunicación. Junto a su aparición, corre la voz de su enfermedad. Como nos explican los narradores de Ardis, las gentes de los aires, Varick muere porque, al decidir quedarse en la Tierra, sumergido en el océano, no sólo entra en la temporalidad y en la contaminación atmosférica, sino que, sobre todo, deja paso al Pensamiento, al parásito. Es el peligro del que hablaban Mr. Alkan y los magos de Demonia, la peste roja de Terra, el inicio de la destrucción del planeta que amenaza a los otros mundos de la Rueda y que coincide con el final sangriento y absurdo, real, histórico, de nuestro siglo XX.

Varick muere el 1 de abril del año 30 de la era de Varick. Ese día Marcelo lee su inacabada novela desde el principio, consigue leerse a sí mismo como si fuera otro y, por fin, se da cuenta de que es un buen escritor. Había encontrado ya su propia «danza del ser interior», como Rita, sólo que no había sido capaz de verlo. A la mañana siguiente, Marcelo y Rita ven el Planeta Análogo en los cielos de Nueva York, una visión continua y duradera, y se unen al grupo de la Sociedad Filarmónica para iniciar el peregrinaje a bordo del Kulffenio II hacia el Monasterio Perdido, hacia el Planeta Análogo.

El fin de la era de Varick, como ocurría con el final de La música del mundo, es, en realidad, la promesa del comienzo de una nueva vida: «para los que seguían vivos aquella mañana de primavera nada había terminado y todo, absolutamente todo, estaba a punto de comenzar» (ibíd.: 599), incluida la propia novela.

\section{REFERENCIAS BIBLIOGRÁFICAS}

Alonso, Santos (2003), La novela española en el fin de siglo 1975-2001. Madrid: Mare Nostrum Comunicación.

Augé, Marc (2001), Ficciones de fin de siglo. Barcelona: Gedisa.

Escohotado, Antonio (1999), Caos y orden. Madrid: Espasa Calpe.

FoucAult, Michel (1966), Las palabras y las cosas. Una arqueología de las ciencias humanas. México D.F.: Siglo XXI, 1997.

García Galiano, Ángel (2004), El fin de la sospecha. Calas significativas en la narrativa española (1993-2003). Málaga: Universidad.

Gracia, Jordi (coord.) (2000), Los nuevos nombres: 1975-2000. Primer suplemento. Barcelona: Crítica. 
GuElbenZu, José María (1998), «La travesía del desfiladero. Narradores españoles de los noventa», Revista de Libros, n. ${ }^{\circ}$ 17, pp. 41-43.

- (2000), «Otros anhelos», Revista de Libros, n. ${ }^{\circ} 39$, pp. 42-43.

IBÁÑEZ, Andrés (1995), La música del mundo o El efecto Montoliu. Barcelona: Seix Barral.

- (1999), El mundo en la era de Varick. Madrid: Siruela.

- (2002), «Paisaje para después de la posmodernidad», en Eduardo Becerra (comp.), Desafios de la ficción. Alicante: Universidad.

- (2003), La sombra del pájaro lira. Barcelona: Seix Barral.

JAMESON, Fredric (1984), El posmodernismo o la lógica cultural del capitalismo avanzado. Barcelona: Paidós, 1991

LANGa PizARro, M. Mar (2000), Del franquismo a la posmodernidad: la novela española (1975-1999). Análisis y diccionario de autores. Alicante: Universidad.

LóPEZ MuRCIA, Pedro (1996), «Entrevista con Andrés Ibáñez», El Urogallo, n. ${ }^{\circ} 127$, pp. 16-23.

LYOTARD, Jean-François (1979), La condición posmoderna. Madrid: Cátedra, 1998.

McHale, Brian (1987), Postmodernist Fiction. Londres: Methuen.

Pozuelo Yvancos, José María (2004), Ventanas de la ficción: narrativa hispánica, siglo XX y XXI. Barcelona: Península.

Trejo Álvarez, Juan (2003), «Andrés Ibáñez», Lateral, n. ${ }^{\circ}$ 105, p. 28. 